\title{
Technology of High Resolution CT Study on the Application of Pore Structure Research in Tight Oil Reservoir
}

\author{
SUN Le ${ }^{1}$, WANG Zhizhang ${ }^{2}$,YU Xinghe ${ }^{1}$,Ma Haiyang ${ }^{3}$ \\ 1. School of Energy Resource, China University of Geosciences, Beijing, 100083 \\ 2. College of Geosciences, China University of Petroleum, Beijing 102249
}

3. Wuqi work zone, Oil Recovery plant No.3, Changqing Oilfield Corp. Ltd, 717600

\begin{abstract}
Keywords: 3D CT; Fengnan Area in Junggar basin; tight oil reservoir; the microscopic pore structure
\end{abstract}

\begin{abstract}
Combined with the scanning electron microscopy (sem), mercury injection test and other microscopic experiment technology, technology of high-resolution 3D reservoir characterization based on the CT imaging was used to sduty the microscopic pore structure of tight oil reservoir in Fengnan Area, sourtheast of junggar basin. From macroscopic to microcosmic, in accordance with the principle of 2D to 3D, the experiments went on one by one, aiming to optimize the experiment sample. Some samples with a diameter of $65 \mu \mathrm{m}$ was derived and scanned by high-resolution Nano-CT, then a three-dimensional texture model of nano-scale pores was established and then the porosity datas of samples in different depth could be obtained and analysized .A clear understanding of the size, shape, spatial distribution and connectivity of the pore throat could be got as well. Experimental analysis shows that, on a micrometer scale, the size of experimental sample pore throat varies violently, and their radius range from 2 to $50 \mu \mathrm{m}$, distributed in or between grains isolatedly or in a shape of a band. The pore throats are fewer but account for a large pore volume. On a nanometer scale, the radius of pores mainly range from 0.05 to $0.3 \mu \mathrm{m}$, and the quantity of nanoscale pores increases. The pore throats are arranged in the shape of tube and ball inside or on the surface of mineral particles (crystals). The ball-shaped micropores in nanoscale, often isolate in the 3D space, show the poor connectivity and consequently act as the reservoir space. The porosities calculated using the Nano CT are close to the results analysized by core samples.
\end{abstract}

\section{Introduction.}

In recent years, the exploration and development of tight oil have been widely concerned in the world. Both the reservoir characteristics and accumulation mechanism of tight oil\&gas are different from those of conventional oil\&gas reservoirs, especially in the aspect of microscopic pore structure in reservoirs, where the study has been transformed from microscale to nanoscale ${ }^{[1-3]}$. The tight oil reservoirs are mainly tight sandstones, compacted limestones and dense carbonate rocks. The reservoir physical property is poor, with complex connectivity of nanoscale pore and throat ${ }^{[4]}$. In China, tight oil reservoirs are of terrestrial origin and with low porosity and permeability. Abundant tight oil resources have been discovered in Lu Caogou Formation of Permian in Junggar basin, Yanchang Formation of Triassic in Erdos basin and Jurassic bed in Sichuan basin. What's more, the in-place resources of each of these basins are above $15 \times 10^{8} \mathrm{t}^{[5]}$. It has been found that the microscopic pore structures in tight oil reservoirs, an important index in reservoir evaluation, are closely related to oil and gas distribution law, accumulation model, percolation mechanism and reservoir protection. International progresses in microscopic pore structures in tight oil reservoirs have been made, such as the classification and origins of nanoscale pores and throats and development of digital core technology. In addition, in the research of unconventional oil and gas reservoirs in China, nanoscale pores which are less than $1 \mu \mathrm{m}$ in diameter, have first been found by means of field emission scanning electron microscope (FESEM) and Nano-CT reconstruction technology, forming the primary connected pore space of tight reservoirs ${ }^{[6]}$. 
Pore structure is an important factor for reservoir physical property. In particular, microscopic pore structure is a key factor controlling the porosity and permeability in tight reservoirs dominant by nanoscale pores and throats. Deposition and Diagenesis are two key factors for various pore types ${ }^{[7-9]}$. Complex structures and strong heterogeneity in reservoirs ${ }^{[10]}$. The characterization of microscopic pore structure has become an important part of tight reservoir research. The laboratory technique applied in reservoir pore structure analysis has gradually appeared multidisciplinary characteristics $^{[11-12]}$. Based on mineral refractive optics, the sample pore structure can be studied by the polarization microscope with a limiting resolution of $0.2 \mu \mathrm{m}$, under which pores and throats, and their connective 2D structure can be directly observed by casting thin sections, and be quantitatively characterized through analyses of pore and throat types, plane porosity and pore-throat coordination number. Scanning electron microscope(SEM) can also be applied in further systematic research on mineral composition, texture and structure, pore type and its origin, cementation degree and secondary change, with a high limiting resolution of $0.8 \sim 20 \mathrm{~nm}$, but it is comparatively difficult to reflect the information of pore and throat $3 \mathrm{D}$ distribution and connectivity ${ }^{[13-15]}$. Through capillary force test to indirectly measure the size and distribution of pore and throat, mercury intrusion method is applicable in micropore size measurement with a limited measuring range. X-ray fault imaging technology is feasible in high speed rock samples scanning and imaging, micro-nano CT analysis of rock samples with different sizes, not only reflecting the integral information of pore and throat structure, but also characterizing the heterogeneity of microscopic pore and throat distribution in tight reservoirs. The scanning images are digitalized to reconstruct 3D pore and throat structure model and they can show the microscale and nanoscale pore and throat structure from different angles ${ }^{[18-20]}$. In this paper, micro and nano-CT technology, combined with other laboratory technologies, are deployed to characterize the microscopic pore structures in tight oil reservoir of Fengcheng formation in Fengnan area of Junggar basin.

\section{Regional Geological Conditions}

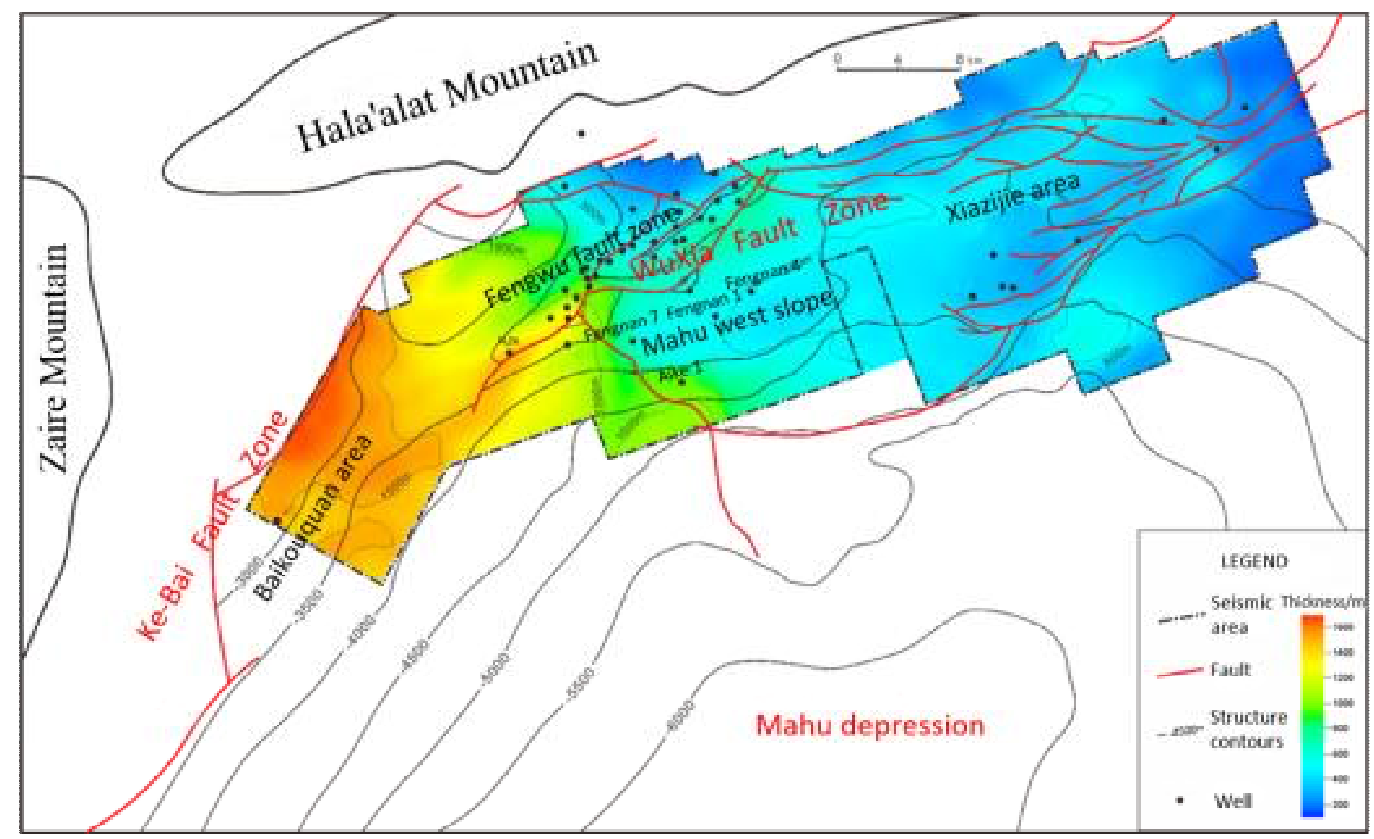

Fig.1 the geographical location of Fengcheng-Wuxia area

Wuxia area, located in the northwest margin of Junggar Basin, is in the south of Hala'alat mountain, stretching from Baikouquan area in the west, with the Mahu depression in the southeast are. From west to east, this area includes Fengwu fault zone, Mahu west slope, and the Xiazijie area (Fig. 1). It is a NE-SW fault-fold belt, influenced by multi-phase structural superposition including Hercynian movement, Indosinian movement, Yanshan movement, Himalayan movement. West slope 
structure of Mahu is a gently SE-dipped monocline, with the anticlines, nose structures and low amplitude platforms developed locally. The study area covers an area of $1,010 \mathrm{~km}^{2}$, with 46 wells drilled in the Fengcheng Formation.

The study area successively deposited and filled with Jiamuhe formation $\left(\mathrm{P}_{1} \mathrm{j}\right)$, Fengcheng formation $\left(\mathrm{P}_{1} \mathrm{f}\right)$, Xiazujie formation $\left(\mathrm{P}_{2} \mathrm{X}\right)$, lower Wuerhe formation $\left(\mathrm{P}_{2} \mathrm{~W}\right)$ and Baikouquan formation $\left(\mathrm{T}_{1} \mathrm{~b}\right)$, lacking of upper Wuerhe formation $\left(\mathrm{P}_{3} \mathrm{w}\right)$ (Table 1). And as the target stratum, the eastern pinch-out Fengzu formation, the thickness of which is $400 \sim 1400 \mathrm{~m}$, is divided from bottom to top into Feng-1, Feng-2 and Feng-3 members.

Table.1 stratigraphic profile of wuxia area

\begin{tabular}{|c|c|c|c|c|c|}
\hline aretham & system & seris & fcrmaticn & member & Itholsgic description \\
\hline Mesozoic & Triassic & $T_{-}$ & $T_{1} b$ & & \multirow{3}{*}{ interbedding } \\
\hline \multirow{7}{*}{ 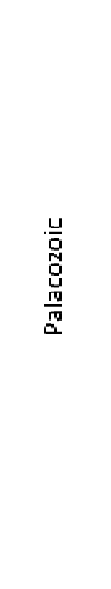 } & \multirow{7}{*}{ Permian } & \multirow{3}{*}{$P_{3+1}$} & \multirow[t]{2}{*}{$\mathrm{F}_{3} / \mathrm{N}$} & $P_{3} w^{2}$ & \\
\hline & & & & $P_{3} w^{1}$ & \\
\hline & & & \multirow{3}{*}{ P.f } & $F_{1} \mp$ & $\begin{array}{l}\text { mudstone, tolomitic mudstone and dolomitic turf } \\
\text { conglomerate and glutenite, sandstone with small }\end{array}$ \\
\hline & & & & $P_{1} f^{\overline{2}}$ & $\begin{array}{l}\text { dolcmitic tuff, mudstcne and shale, tuffaceous } \\
\text { dolcmite interbed }\end{array}$ \\
\hline & & $P_{1}$ & & $F_{1} f^{1}$ & 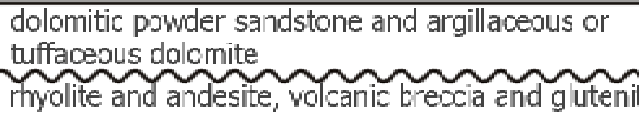 \\
\hline & & & \multirow[t]{2}{*}{$P_{1} \mathrm{j}$} & $\left.P_{1}\right]^{2}$ & $\begin{array}{l}\text { gray tuffeceous breccia conglomerate, sandstane, } \\
\text { rhyclite and basalt }\end{array}$ \\
\hline & & & & $\rho_{-j}{ }^{1}$ & $\begin{array}{l}\text { oeladon volcanic breccia and tuff, andeste, basalt, } \\
\text { gluten te }\end{array}$ \\
\hline
\end{tabular}

The lithology of Fengcheng formation is tight, of which the porosity and permeability is commonly low. The Fengcheng formation reservoir with the fine grain size of primary sedimentation is buried deeply, resulting in the damage of the primary pores. Therefore, the types of reservoir space are mainly secondary solution pores and fractures. The reservoir, in which the radius is small and the connectivity is bad, can be benefited from the fractures. The reservoir physical property in west slope zone where the matrix pore is well developed is bad, while the fault zone in Wuxia and the reservoir in Xiazijie area influenced by the faults and sedimentary environment is relatively good. The Fengcheng foramtion reservoir, of which the porosity ranges from $2 \% \sim 13 \%$, with a average of $4.65 \%$ and the permeability ranges from $0.003 \sim 47.9 \mathrm{mD}$, lower than $1 \mathrm{mD}$ showed in $85 \%$ samples(Fig.2), is characteristic of compaction obviously (Fig.3). Among the reservoir physical property of the members, it is relatively good with the features of "sweet spot" in Feng-2 and Feng-3 members which develops medium pores by a certain extent.
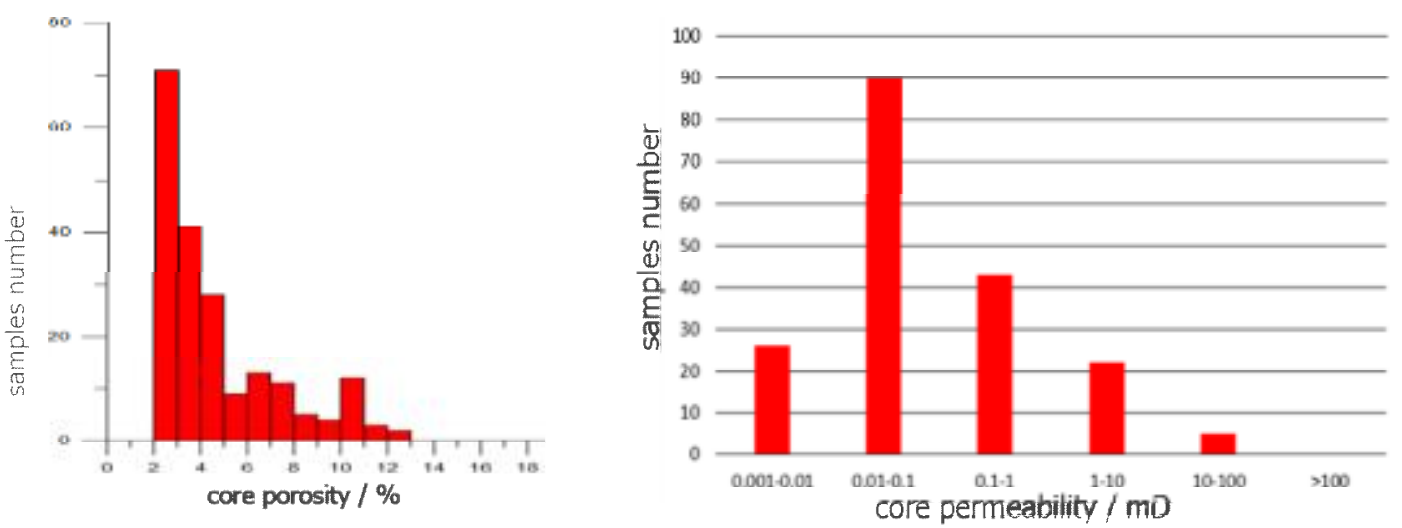

Fig.2 physical properties distribution histogram of reservoir in slope belt Data Source: Fengnan1, Fengnan2, Fengnan3, Fengnan4, Fengnan7, Aike1 


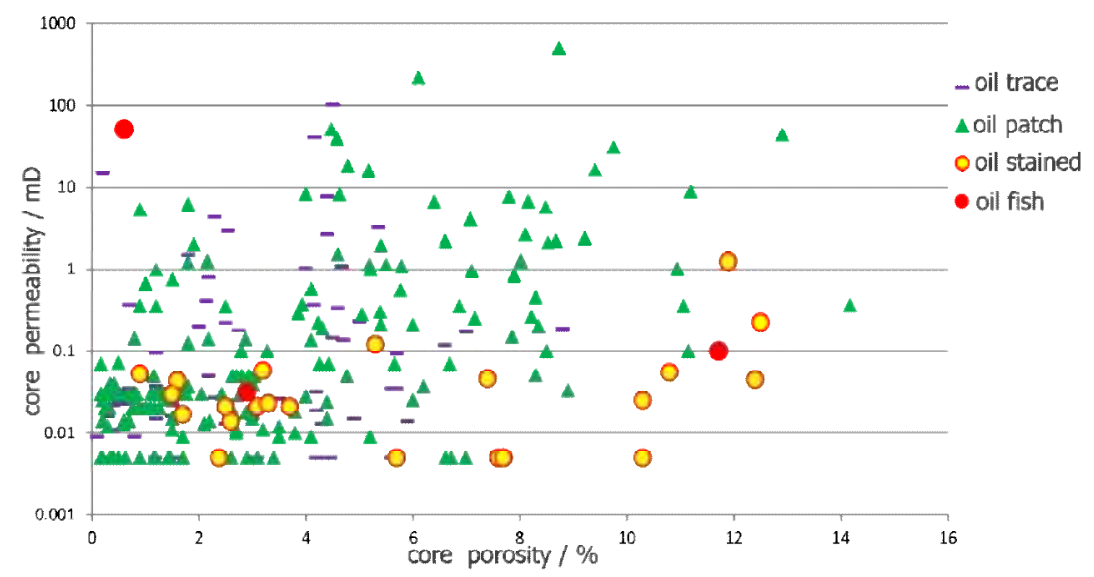

Fig.3. porosity-permeability relationship diagram with different oil sexual in Fengcheng Formation, in Wuxia area

The west slope of Muhu depression is one of the three key areas for exploration study of tight oil and gas in Junggar Basin. As one of the most important prolific hydrocarbon depressions in Junggar Basin, Fengcheng formation with high abundance of organic matter, good type of organic matter and high maturity is good source rock and also the oil and gas origin of many horizons in the west margin of Junggar Basin. In the past, the exploration study of the Permian Fengcheng formation mainly concentrated on the structural "sweet spot" in the nose highs or others in Wuerhe area and, however, the exploration was clearly lower. From September 2011 to 2012, drilled by Fengnan 7 well, commercial oil flow with a rate of $12.3 \mathrm{~m}^{3} / \mathrm{d}$ was firstly exploited from the tight tuffaceous dolomite rock in the Feng-3 member of the west slope in Muhu depression. That was the great breakthrough for the west slope of Mahu depression where fractures was undeveloped producing commercial tight oil flow in the dolomite reservoir. As the exploration area for tight oil, the vast areas in the west slope with tight reservoir far from fault belt, just were drilled 6 well of which each had acquired oil. Therefore, the study area has large exploration potential.

\section{Experimental Principle}

The micro and nano-CT technology was first used in the area of medical diagnosis, which now has extended to the petroleum exploration and played a very tremendous role in the reservoir description. The UltraXRM-L200, MicroXCT-400, produced by Xradia Company in America, can provide the photon energy arrange between the $8 \mathrm{kev}$ to $150 \mathrm{kev}$, widely used to probe the distribution, the size and connection of the pores among the tight sandstone, shale and carbonate reservoirs, Until to now, N-CT can improve the resolution to $50 \mathrm{~nm}$, in the meaning while, micro CT can improve the resolution to $0.5 \sim 20 \mu \mathrm{m}$, with the sample diameter arrange between 2 to $50 \mathrm{~mm}$. The X-CT device can decrease the requiring to the core and the sample in the field, the sample could be damaged and pieces of fragments. With the help of the CT, we can get abundant parameters about the pore and float ${ }^{[21-22]}$. 


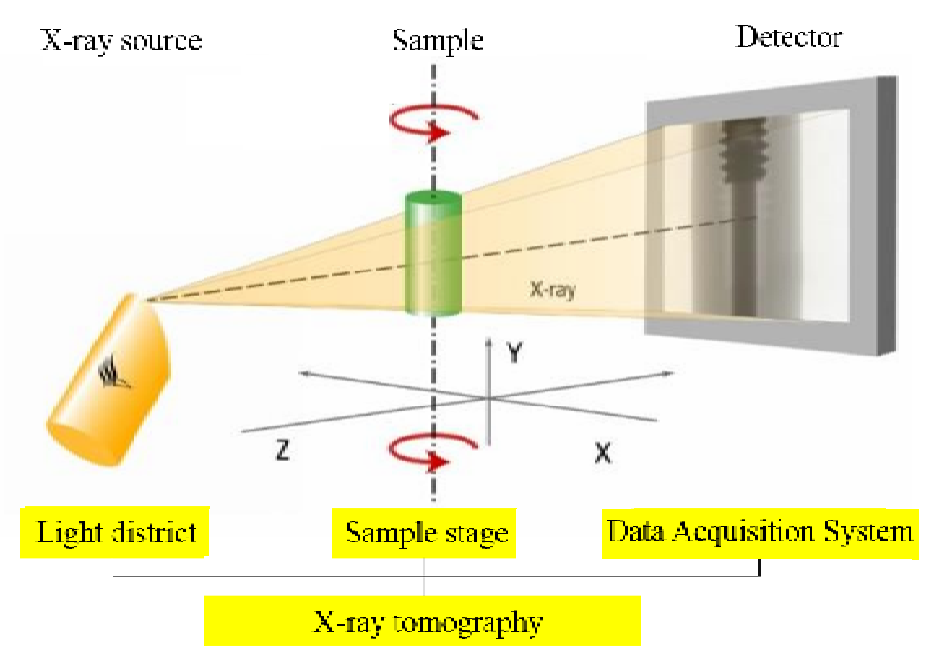

Fig.4 the schematic drawing of X-CT device principle

Using the X-ray microscopic Imaging optical lenses, the X-CT device is a high resolution non-invasive research methods of three-dimensional reconstruction of microscopy, x-ray scans from more than one direction to pass through objects section, probing internal structure of matter, in order to adjust the intensity of object's X-ray and obtain the value with respect to X-ray CT.

The optical principle is as below. An X-ray irradiates through the focusing optical lens on the sample, with the images amplified by a zone plate lens. Then the images are captured by the CCD (Charge-Coupled Device) image sensor ${ }^{[23]}$ (Fig.4). The foundation of the CT lie in the X-ray attenuation, which was determined by the material composition, density and the direction of the beam. The attenuation of the X-ray can be surmised by the formula:

$$
I=I_{0} e^{-\sum_{i} u_{i} x_{i}}
$$

In the formula, $I$ is the intensity of X-rays passing through the object; $I o$ is the original $X$-ray intensity; $\mu$ is the attenuation coefficient of the $\mathrm{i}$-th component to the $\mathrm{X}$-ray; $x_{i}$ is the path length of the $\mathrm{X}$-rays passing through the $\mathrm{i}$-th component ${ }^{[24]}$.

Simply speaking, CT was used to rebuild the two-dimensional grayscale images and to get the three dimensional images with the help of image processing software. Due to the lower standard of the grayscale, the edge of images might be blurred. Though the binariztion of the boundary we can defined the boundary as the discrete discrete "0" and "1", which will provide the path to the following three dimensional display and calculation (Fig.5, Fig.6).

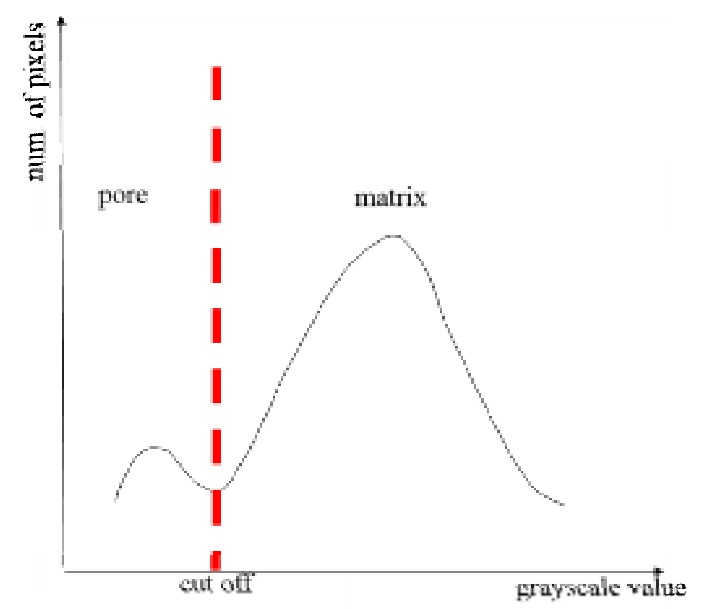

Fig.5 distribution diagram of grayscale image 


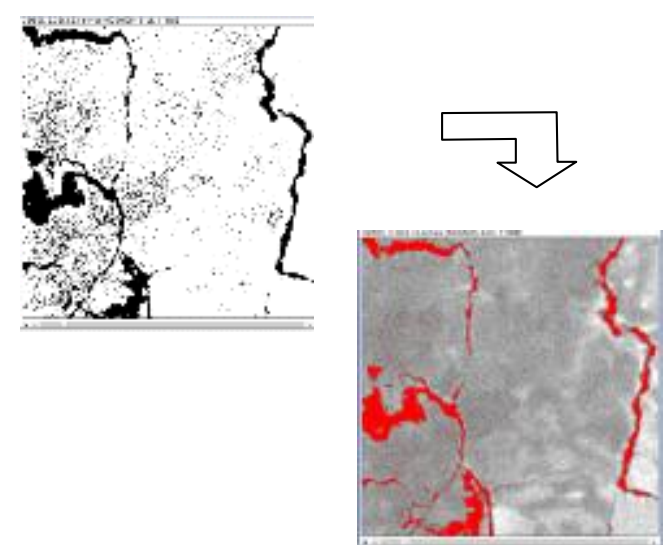

Two-dimensional pore coloring

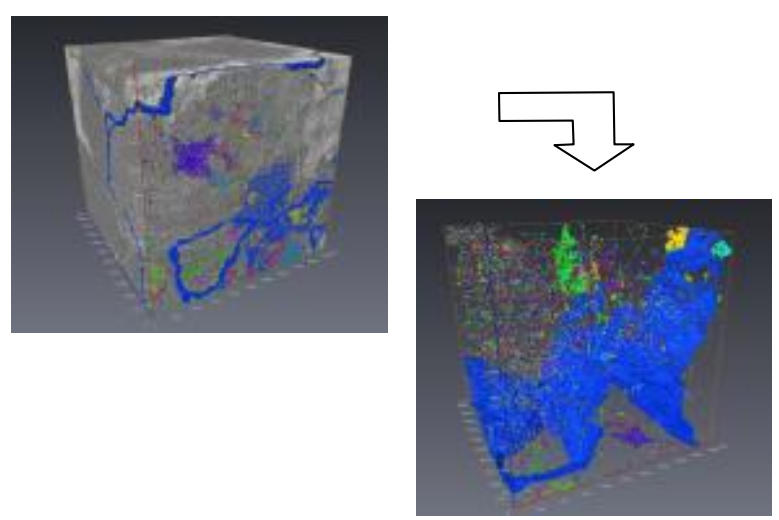

three-dimensional pore coloring and hollowing

Fig.6 2D and 3D images rebuilding

\section{Research Approach}



Fig.7 typical well column of Fengnan Area

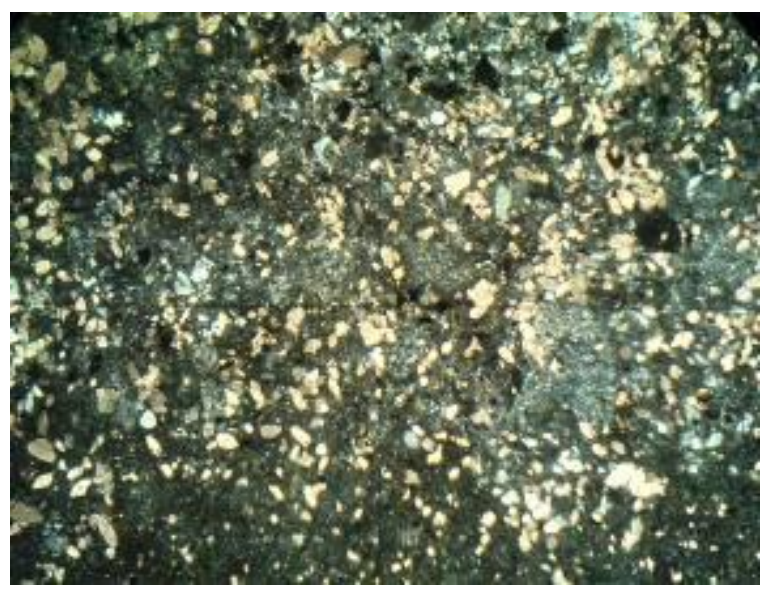

Fengnan 1, 4196.56m, dolomitic muddy fine sandstone $\Phi=6.0 \% \mathrm{~K}=1.02 \mathrm{mD}$

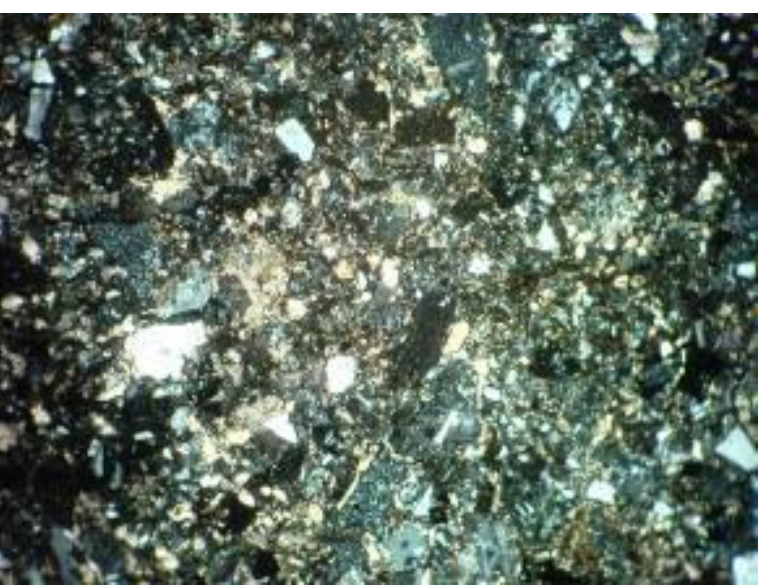

Fengnan 4, 4580.8m, dolomitic fine sandstone $\Phi=5.3 \% \mathrm{~K}=0.121 \mathrm{mD}$

Fig. 8 casting lamella of typical samples 
The experiment samples in this study were taken from Fengcheng Formation in the area of Fengcheng. The heterogeneity in the longitudinal direction is strong of tough oil in Fengcheng Formation. Lithology is mainly dolomitic sandstone, dolomitic mudstone, tuffaceous dolomite, etc (Fig.7), and the grain is fine. Physical properties are affected by sedimentary facies and dolomitic content (Fig.8) The pore type is mainly intragranular pore, with irregular shape, most of which are isolated. While intergranular dissolution pores are developed, most of which are harbor shape and strip, etc, and many are filled with clay minerals (fig.9). Pore structure parameter is an important part of the pore structure characterization, which can be divided into characteristic throat size, sorting, connectivity and control fluid movement. Table 2 is the reservoir pore structure parameter table of Fengcheng Formation by statistical analysis by mercury intrusion test. Analysis shows that the pore radius of Feng Three member is large, with $0.97 \mu \mathrm{m}$ of the maximum pore throat radius, smallest separation coefficient, and good connectivity pore throat. Average capillary radius of sample is $0.17 \mu \mathrm{m}$, in which the largest one is Feng Three member, as $0.29 \mu \mathrm{m}$, while the smallest one is Feng One member, as $0.07 \mu \mathrm{m}$. The volume percentage of non-saturated pore throat is large, that is non-wetting phase proportion of pore throat is large.

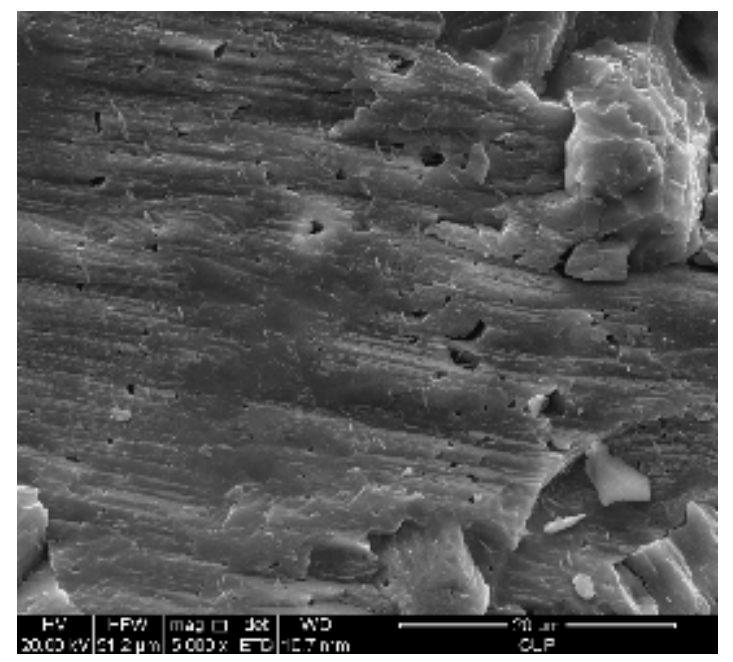

a Intragranular solution pore $(4259.5 \mathrm{~m})$

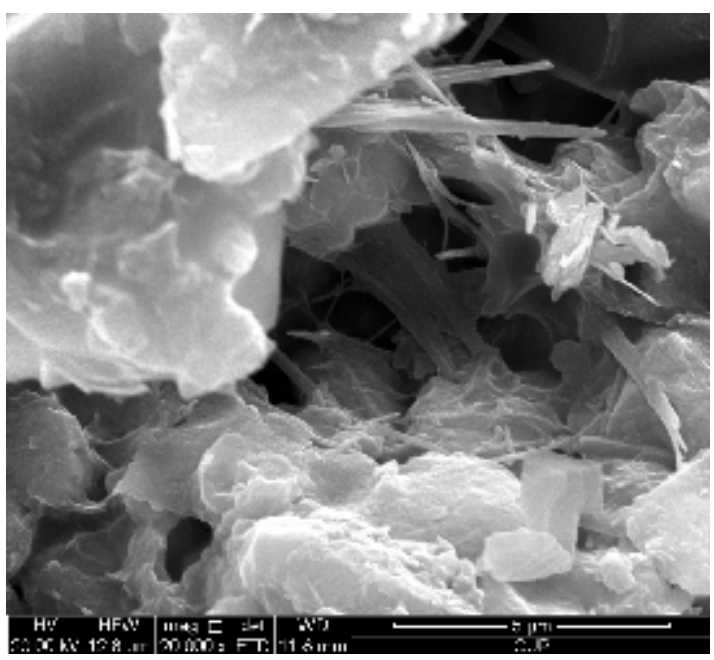

$\mathrm{b}$ Intergranular filled and bridged by illite (4581.5m)

Fig.9 SEM graphs of samples from Fengnan 1

Table 2 Scanning by electron microscopy of Fengnan 4 sample

\begin{tabular}{cccccccc}
\hline reservoir & porosity & $\begin{array}{c}\text { Sorting } \\
\text { coefficient }\end{array}$ & $\begin{array}{c}\text { maximum } \\
\text { pore throat } \\
\text { radius } \mu \mathrm{m}\end{array}$ & $\begin{array}{c}\text { Displacement } \\
\text { pressure MPa }\end{array}$ & $\begin{array}{c}\text { average } \\
\text { capillary } \\
\text { radius } \mu \mathrm{m}\end{array}$ & $\begin{array}{c}\text { Efficiency of } \\
\text { mercury } \\
\text { withdrawal }\end{array}$ & $\begin{array}{c}\text { Pore throat } \\
\text { volume ratio }\end{array}$ \\
\hline Feng Three & 3.61 & 1.06 & 0.97 & 2.09 & 0.29 & 19.1 & 5.24 \\
\hline Feng Two & 2.67 & 1.61 & 0.6 & 1.81 & 0.14 & 19.5 & 5.5 \\
\hline Feng One & 3.06 & 1.34 & 0.26 & 3.91 & 0.07 & 21.6 & 7.36 \\
\hline
\end{tabular}

Observed the cast thin section, scanning electron microscopy, micro CT, selected sample that the best characterization of reservoir pore development of Fengcheng Formation in the area of Fengnan, and manufactured cylinder of diameter $65 \mu \mathrm{m}$. Use of nano-CT technology to construct nanoscale three-dimensional model of the micro pore throat, and get microscopic pore throat structure of nano-scale resolution. Calculate the parameter such as porosity, pore throat radius of sample. combine with other microscopic experimental techniques, analysis the pore structure of Fengnan area. Table 3 shows the information of test sample preferably. 
Table 3 Nano-CT sample statistics

\begin{tabular}{cccccc}
\hline sample & well & depth & lithology & porosity / \% & location \\
\hline sample 1 & Fengnan 1 & $4123.3 \mathrm{~m}$ & Argillaceous dolomite & 3.86 & Feng Three \\
\hline sample2 & Fengnan 1 & $4196.3 \mathrm{~m}$ & Dolomitic mudstone & 2.18 & Feng Two \\
\hline sample3 & Fengnan 4 & $4581.5 \mathrm{~m}$ & $\begin{array}{c}\text { Dolomitic fine } \\
\text { sandstone }\end{array}$ & 2.50 & Feng One \\
\hline
\end{tabular}

\section{Experimental Results}

The scale of rock sample used by Nano-CT technique is too small, and therefore a reasonable choice of sample locations is critical. Figure $3 \mathrm{a}$ is the results of microns CT of sample 2. As can be seen, the pore is developed, in which is large of local position. The diameter is about $50 \mu \mathrm{m}$, and strong heterogeneity. There is development zone of micro pores in dolomitic mudstone sample. But due to lack of picture resolution, pore structure characteristics of the samples were still needed higher-resolution CT imaging analysis.

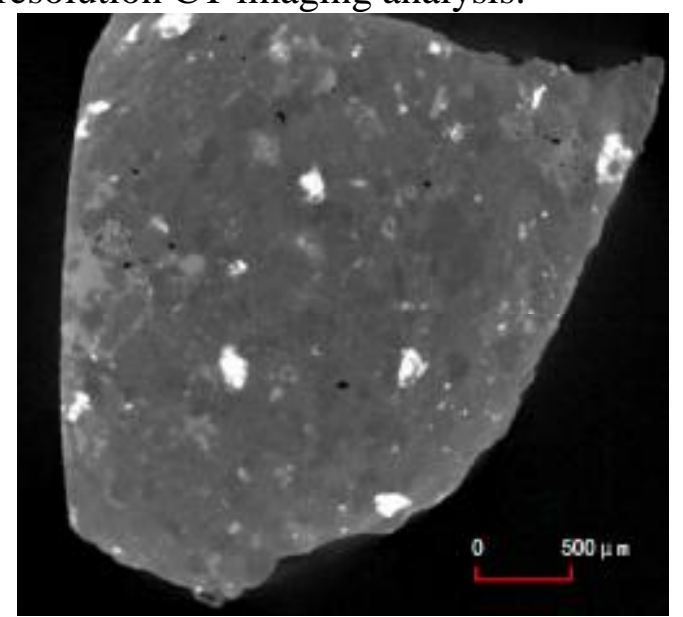

(a) micron-CT figure

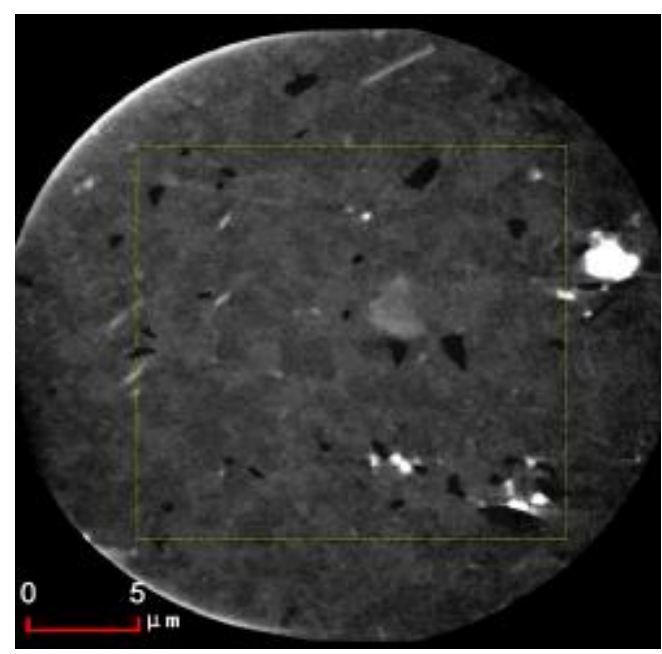

(b) Nano-CT figure

Fig.10 Multiscale CT graphs of sample in Feng Two member, Fengnan 1

For micron-scale CT scanning structures, stomatal development zone in micro nano manufacturing standard sample CT scan, get a resolution of 901 two-dimensional scanned image of 50nm(Fig.10). Dimensional scanning image analysis shows, nanoscale pore throat is overall development in samples. Microporous is banded and curved lamellar. They are mainly in the mineral particles, belong intragranular pores or intercrystal pores. Pore throat radius mainly between 0.05 $0.3 \mu \mathrm{m}$.

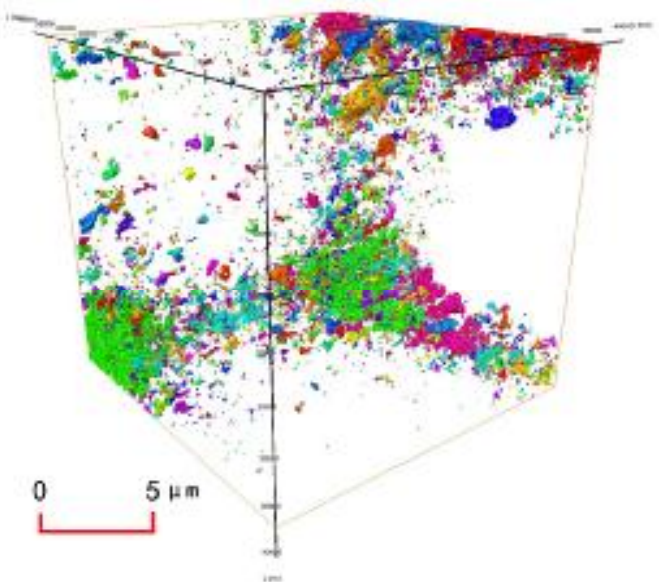

(a) 3D pore throat distribution

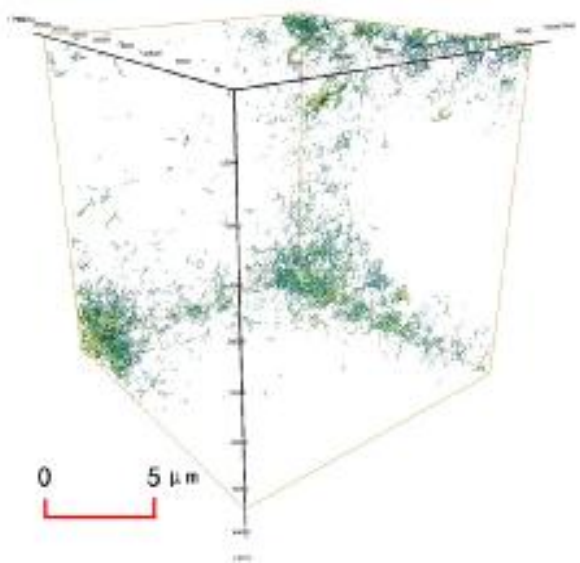

(b) throat simulation analysis

Fig. 11 result analysis figure of Nano-CT of sample in Feng Two member, Fengnan 1 
In the light of the picture of dimensional pore and throat distribution structure (Fig.10b, Fig.11a), nanoscale pore throats are superimposed, spherical, short tubular mineral particles distributed in the interior and surface. The connectivity of pore is poor, with distribution into isolated. Micron pore was thick tubular and strip surrounding the particles, with good connectivity. As well as reservoir space, they are significant seepage channel. Figure $11 \mathrm{~b}$ is throat distribution obtained by numerical simulation. Throat mainly located between micro- and tubular nano-scale pores. Throat radius size ranged from $0.04 \sim 0.20 \mu \mathrm{m}$ by statistics (Fig.13). According to the statistical data as Figure 12 and Figure 14 shows that pore radius of sample 2 mainly between $0.05 \sim 0.30 \mu \mathrm{m}$, accounting for $96 \%$ of the number of all the pores, but the pore volume of the radius of $0.3 \mu \mathrm{m}$ or less accounting for $18 \%$ of total volume only. The distribution of Micron pore is less, but with a large proportion of the volume. Radius that greater than $1 \mu \mathrm{m}$ accounts for $58.5 \%$ of total volume. Average pore throat radius of sample 2 is $0.16 \mu \mathrm{m}$, while it is $0.14 \mu \mathrm{m}$ measured by mercury intrusion of Fenger Member, both are close.

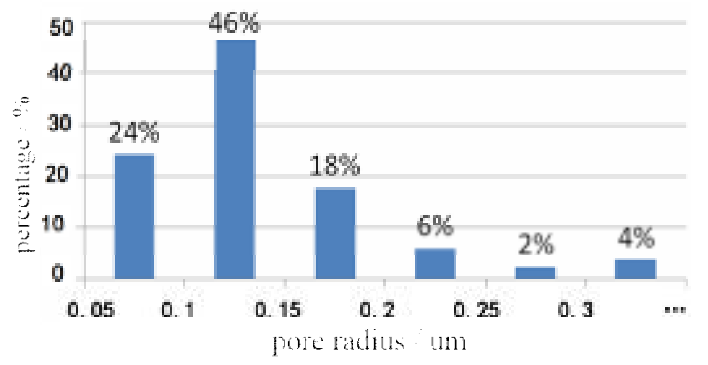

Fig.12 pore throat size frequency distribution histogram of sample 2

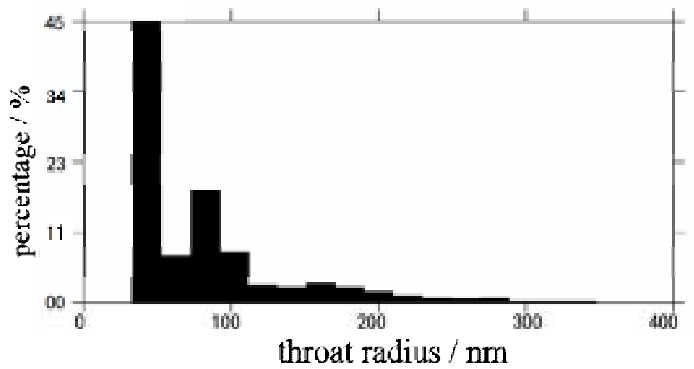

Fig.13 analog throat size frequency distribution histogram of sample 2

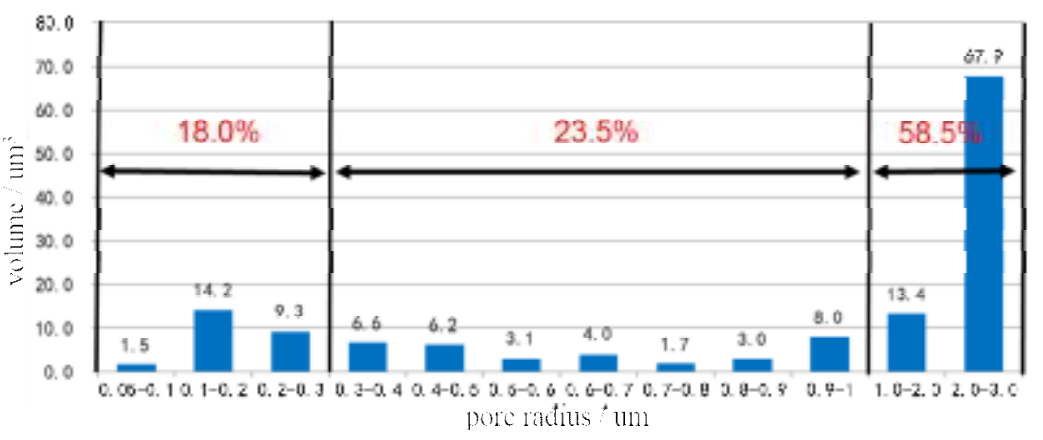

Fig.14 the volume distribution histogram occupied by different pore throat size of sample 2

Based on the scanned dates of Nano-CT, a three-dimensional pore model was established. By numerical simulating and counting the volume of the pixels occupied by the pores, the porosity of sample two was $1.90 \%$, it was $2.18 \%$ through core analysis, and $2.67 \%$ by the mercury method. Some deviation existed by the reason that the scale of the samples were too small, and the selected samples used for the Nano-CT analysis maybe not come from the place where micropores developed the most. The porosities of sample 1 and sample 3 calculated by Nano-CT were $3.98 \%$ and $2.56 \%$ separately, which were very close to the core analysis data. Using the technology of Nano-CT, combined with slice analysis, scanning electron microscopy, mercury injection test and other experiment technology, it showed that tight oil reservoir in Fengcheng formation characterized low porosity and tightness. The types of reservoir pores contains primary pores, intergranular pores and secondary dissolution pores, and the radius of intergranular pores were usually no larger than a few microns. The main pores type developed in the reservoir were the secondary dissolution pores with different sizes, which were formed by the dissolution of dolomite, calcite, feldspar, borosilicate sodalite and other minerals. The pores have poor structure, isolated distribution, and poor connectivity. The throat radius was finer, 
common lower than $1 \mu \mathrm{m}$. The distribution uniformity of the pores were change from moderate to poor, and the values of physical parameters to the corresponding reservoir were commonly low. Almost all the porosity of the pores was less than $3 \%$ and the permeability was lower than $0.1 \mathrm{mD}$ commonly.

\section{Conclusions}

Using the technology of high-resolution CT 3D imaging, we can characterize the pore structure characteristic of the tight oil reservoirs and understand the microscopic pore shape, size, distribution and connectivity at different scale. The microscopic pore characteristic of Fengcheng formation in Wuxia Fengnan Area have different manifestations at different scales. Micron pores have a variety of forms while spherical pores have a poor connectivity and an isolated 3D shape, working only as the reservoir space. The number of nanopores is increasing in the nanoscale scale. Pores and throats superimposed on each other, which were distributed in the internal and surface of mineral particals (crystals), and the shapes of them appeared tubular or spherical while the radius range from $0.04 \mu \mathrm{m}$ to $0.5 \mu \mathrm{m}$. The nanoscale short tubular pores have some connectivity and have the dual function of both throats and pores. To research on the microscopic pores structure of tight oil reservoir, it's needed to make use of new ideas and new technologies which are different to the methods for conventional reservoir study, aiming to get the accurately, scientific and real understanding. Technology of CT imaging provides the basis for an accurate understanding of characteristics of microscopic pore structure of tight oil reservoir. Combined with the advantages of other microscopic experiment technologies, a comprehensive understanding of pores structure characteristic in the tight oil reservoir will be achieved eventually. The technology of high-resolution CT 3D imaging explored a new approach for nanoscale pore structure characteristic in the tight oil reservoir.

\section{References}

[1] You Yuan, Niu Xiaobing, Xin Honggang. The foreign study of microcosmic pore structure of tight oil reservoirs and its Implications for the Ordos Basin[J]. Petroleum Technology

Forum.2013,01(3):13-18.

[2] Zou Caineng, Zhang Yaguang, Tao Shizhen, et al.Geological features, major discoveries and unconventional petroleum geology in the global petroleum exploration[J], Petroleum Exploration and Development. 2010,37(2).

[3] ZOU Caineng, ZHU Rukai, WU Songtao, et al.Types, characteristics, genesis and prospects of conventional and unconventional hydrocarbon accumulations: taking tight oil and tight gas in China as an instance[J],Acta petrolei Sinica, 2012,33(2):173-187.

[4] Zhu Rukai, Bai Bin, Cui Jingwei, et al. Research advances of microstructure in unconventional tight oil and gas reservoirs[J], Journal of palaeography. 2012,33(2):173-187.

[5] Zou Caineng, Yang Zhi, Tao Shizhen, et al,Nano-hydrocarbon and the accumulation in coexisting source and reservoir[J], Petroleum Exploration and Development. 2012,39(1):13-20.

[6] Zou CN, Zhu RK, Bai B, Yang Z, Wu ST, Su L, Dong DZ and Li XJ. First discovery of nano-pore throat in oil and gas reservoir in China and its scientific value[J]. Acta Petrologica Sinica.27(6):1857-1864.

[7] Li Haiyan, Xu Zhangyou. Microscopic characteristics of pore structure and classification evaluation of low permeability reservoir in Xinli Oilfield[J], Petroleum Geology and Recovery Efficiency. 2009,16(1):17-23.

[8] Li Haiyan, Yue Dali, Zhang Xiujuan.Characteristics of pore structure and reservoir evaluation of low permeability reservoir in Sulige gas field. Earth Science Frontiers. 2012,19(2):133-139.

[9] HE Tao, WANG Fang, WANG Lingli, Characteristics of micro-pore structure of tight sandstone reservoir: A case study from Chang 7 reservoir of Yanchang Formation in Ordos Basin[J].Lithologic Reservoirs.2013,25(4):23-28 
[10] Tang Haifa, Peng Shimi, Zhao Yanchao, et al.CHARACTERISTICS OF PORE STRUCTURE AND RESERVOIR EVALUATION IN H2+ 3 TIGHT GAS RESERVOIR, DANIUDI GAS

FIELD[J]. Jmineral Petrol. 2006,26(3):107-113.

[11] Hao Lewei, Wang Qi, Tang Jun. Research progress of reservoir microscopic pore structure[J]. Lithologic Reservoirs.2013,25(5):124-128.

[12] Luo Shunshe, Wei Wei, Wei Xinshan, etc. Tight Sandstone microstructure characterization and development trend[J]. Oil and Gas Technology2013,35(9):5-8.

[13] Zou Chunyan, Luo Rong, Li Zirong, et al. Application of SEM on Clay Mineral Study for Clastic Reservoirs[J]. Natural Gas Exoloration and Development. 2005.28(4):4-7.

[14] Liu Weixin, Shi Zhihua, Zhu Ying. APPLICATION OF SEM/EDX ANALYSIS IN

PETROLEUM EXPLORATION AND PRODUCTION[J]. PETROLEUM GEOLOGY \&

EXPERIMENT. 2001,23(3):341-343.

[15] Yu Lifang, Yang Zhijun, Zhou Yongzhuang, et al. The Application Summary of Scanning Electron Microscope（SEM）And Environment Scanning Electron Microscope（ESEM）in Geoscience[J]. JOURNAL OF THE GRADUATES SUN YAT-SEN UNIVERSITY. 2008,29(1):54-57

[16] Ma Wenguo, Wang Ying, Hai Mingyue, et al.Research of pore structure characteristics of cores based on mercury penetration experiments $[\mathrm{J}]$. Experimental Technology and Management.

2013,30(1):66-68.

[17] Wu Yuanyan, Wu Shenghe, Cai Zhengqi. Oil field geology[M]. Petroleum Industry Press.2005:194-205.

[18] Lame O, Bellet D, Di Michiel M, et al. Bulk observation of metal powder sintering by X-ray synchrotron microtomography[J]. Acta Materialia, 2004, 52(4): 977-984.

[19] Sakdinawat A, Attwood D. Nanoscale X-ray imaging[J]. Nature Photonics, 2010, 267(4): 840-848.

[20] Gelb J, Gu A, Fong T, et al. A closer look at shale: Representative elementary volume analysis with laboratory 3D X-Ray computed microtomography and nanotomography[R]. SCA2011-58, 2011. [21] She Min, Shou Jianfeng, Zheng Xingping, et al.3D High Resolution Reservoir Characterization Technique Based on CT Imaging and Application[J].XINJIANG PETROLEUM GEOLOGY. 2011,32(6):664-667.

[22] Arns C H, Bauget F, Limaye A, et al. Pore scale characteriza-tion of carbonates using X-ray microtomography[C] Proceed-ings, SPE Annual Technical Conference and Exhibition, 26-29

September, 2005.

[23] Bai Bin, Zhu Rukai, Wu Songtao, Multi-scale method of Nano(Micro)-CT study on microscopic pore structure of tight sandstone of Yanchang Formation, Ordos Basin[J]. Petroleum Exploration and Development. 2013,40(3):329-333.

[24] Su Na, Duan Yonggang, Yu Chunsheng. Reconstruction of microscopic pore structure in low permeability gas reservoirs by micro-CT scanning:an example from the Upper Shaximiao Formation in Xinchang gas field[J]. Oil \& Gas Geology. 2011.32(54):792-796. 